\title{
EFFECT OF OXYGEN ON CREEP CRACK GROWTH IN
}

PM/HIP NICKEL-BASE SUPERALLOYS

Kenneth R. Bain* and Regis M. Pelloux**

*Formerly Graduate student, Massachusetts Institute of Technology, is senior Research Metallurgist, Allison. Gas Turbine Operation, General Motors Corporation, P. 0. Box 420, Indianapolis, IN 46206.

**Professor, Massachusetts Institute of Technology, Department of Materials Science and Engineering, Cambridge, MA 02139.

\section{Summary}

The creep crack growth rates (CCGR) of four PM/HIP nicke1-base superalloys were measured in a range of CCGR from $10^{-9} \mathrm{~m} / \mathrm{s}$ to $10^{-5} \mathrm{~m} / \mathrm{s}$. The alloys tested were low carbon Astroloy, Mer1-76, low carbon IN-100, and Rene 95. Crack growth rates were measured in air and $99.999 \%$ pure argon at $704^{\circ} \mathrm{C}$. Creep crack growth tests were performed on single edge notched specimens and the crack length was measured using the d.c. potential drop technique. The curve of crack growth versus the stress intensity factor cxhibits three ranges which are dependent upon the initial value of the stress intensity factor. Region I is characterized by slow crack growth followed by Region II where the crack growth has a power law dependency on the stress intensity factor and Region III of fast fracture which is limited by the KIC value of the material. The CCGR of the four alloys in both air and in inert environment are shown to correlate with the stress intensity factor in Region II of the crack growth versus $\mathrm{K}$ curve. The crack propagated along the grain boundaries in the air tests and along the prior particle boundaries in the argon tests. The creep crack growth rates for the four PM/HIP alloys appear to correlate with the effective diffusivity of oxygen along the grain boundaries. 


\section{Introduction}

Creep crack growth (CCG) is a process in which a single macroscopic crack propagates under sustained load at temperatures wel1 within the creep regime $\left(\mathrm{T}>0.4 \mathrm{~T}_{\mathrm{m}}\right)$. The micromechanisms of creep crack growth have been extensively studied (1-5) and are generally recognized to consist of the nucleation, growth and coalescence of grain boundary cavities.

Creep crack growth is a topic of renewed research interest due to the need in the gas turbine industries to design high performance, higher temperature engines. A better understanding of creep and fatigue crack growth is associated with recent attempts to institute a damage-tolerant approach in the design of modern aircraft gas turbines (6). In brief, a damage tolerant design assumes that a component has a flaw (i.e. crack) of a size just below the non-destructive inspection detectable limit. The times to inspection and/or retirement are based on the crack growth rate of the flaw.

Creep crack growth rates have been measured on a wide variety of nickelbase alloys in both air and inert environment (7-16). The results indicate that for different alloys the creep crack growth rates in air can vary by up to four orders of magnitude at a given value of the stress intensity factor, $\mathrm{K}_{\mathrm{T}}$. However, the difference in CCGR between different alloys is usually lower when measured in an inert environment.

The rate of crack propagation in inert environment or vacuum is lower than the rate observed in air under identical loading conditions. This difference in CCGR is so pronounced in some alloy systems that the CCG process can be thought of as a form of high temperature stress corrosion cracking.

Studies of the effect of various environments on the mechanical properties of nickel-base alloys have identified oxygen as one of the main species responsible for the environmental effect in this group of alloys. (1721). Oxygen has been shown to diffuse along the grain boundaries in nickelbase alloys resulting in a loss of ductility and tensile strength at intermediate temperatures (between $600^{\circ} \mathrm{C}$ and $800^{\circ} \mathrm{C}$ ). The depth of oxygen penetration in a high temperature tensile test may be small when compared to the diameter of a tensile bar, but it is a significant portion of the plastic zone size $R_{p}$ near the crack tip of a fracture mechanics specimen. It is important to realize that the rate of grain boundary diffusion of oxygen in nickel-base alloys is sufficient to completely embrittle the highly stressed zone adjacent to the crack tip at high temperatures.

The following research program was undertaken to study the effect of mechanical test parameters and the effect of environment on the CCGR of four PM/HIP nicke1-base alloys of current interest. The four alloys investigated were low carbon Astroloy, Mer1-76, low carbon IN-100, and Rene 95,

\section{Experimental Procedures}

\section{Materials}

Four $\gamma-\gamma^{\prime}$ nicke1-base superalloys were chosen for this study. The alloys were chosen for their varying content of key elements such as $B$ and $C$ and prior particle size. They were produced by HIP processing of PM alloys into 9/16" diameter rods. The powder mesh size for each alloy is given in Table I, along with the maximum particle diameter. Rene 95 was obtained in two mesh sizes. 


$\begin{array}{lcc} & \frac{\text { Mesh }}{\text { Size }} & \frac{\text { Particle Diameter }}{\mu \mathrm{m}} \\ \text { Astroloy } & \underline{\underline{y}} & 149 \\ \text { Mer1-76 } & 100 & 45 \\ \text { IN-100 } & 325 & 250 \\ \text { Rene 95 } & 60 & 250 \\ \text { Rene 95 } & 60 & 125\end{array}$

The heat treatment, Table II, was chosen to yield similar short time tensile properties for all the alloys.

Table II. Heat Treatment

Solution: $\quad 1177^{\circ} \mathrm{C} / 4$ hours/ air cool

Age: $\quad 871^{\circ} \mathrm{C} / 8$ hours/ air cool $982^{\circ} \mathrm{C} / 4$ hours/ air cool $650^{\circ} \mathrm{C} / 24$ hours/ air cool

$760^{\circ} \mathrm{C} / 8$ hours/ air cool

The chemistry along with calculated $\gamma^{\prime}$ volume fraction for each alloy are given in Table III. IN-100 Rene 95 and Astroloy have a coarse grain size, with carbides decorating the grain boundaries. MERL-76 has a finer grain size with large primary $\gamma^{\prime}$ particles along the boundaries.

Prior powder boundaries were easily observed at low magnification in all the alloys tested. Grain boundaries usually coincided with these boundaries. The prior powder boundaries are decorated with large carbides present at the surface of the powder particles. In the case of Rene 95 and Mer1-76, these carbides are known to be columbium carbides, while in Astroloy and in IN-100 they probably are titanium carbides.

Creep crack growth rate tests were conducted at $704^{\circ} \mathrm{C}$ in a creep frame. The temperature was controlled within $\pm 4^{\circ} \mathrm{C}$ in the gauge section of the specimen using a 3-zone resistance heater. Tests were conducted in two environments: air and 99.999\% pure argon. A retort was used in the argon tests. Argon tests were conducted at an overpressure of 5 psig in order to insure no back streaming of air.

A single edge-notched test specimen was used in the CCGR tests. The specimen had side grooves added to prevent crack tip tunnelling.

A d.c. electrical potential drop technique was used to measure the crack length. A current of 20 amps was passed through the specimen and the change in potential acrosss the mouth of the crack was measured as a function of time. A resolution of $50 \mu \mathrm{m}$ increment of crack length was routinely achieved.

\section{$\underline{\text { Resu1ts }}$}

The creep crack growth rates show in general a three-stage behavior similar to the one described in Fig. 1 when they are reported on a log-log plot of $\mathrm{da} / \mathrm{dt}$ versus the stress intensity factor $\mathrm{K}$. Stage $I$ corresponds to an initial transient where da/dt varies very rapidly with the loading parameter. The extent of this stage with respect to the other stages depends very much 


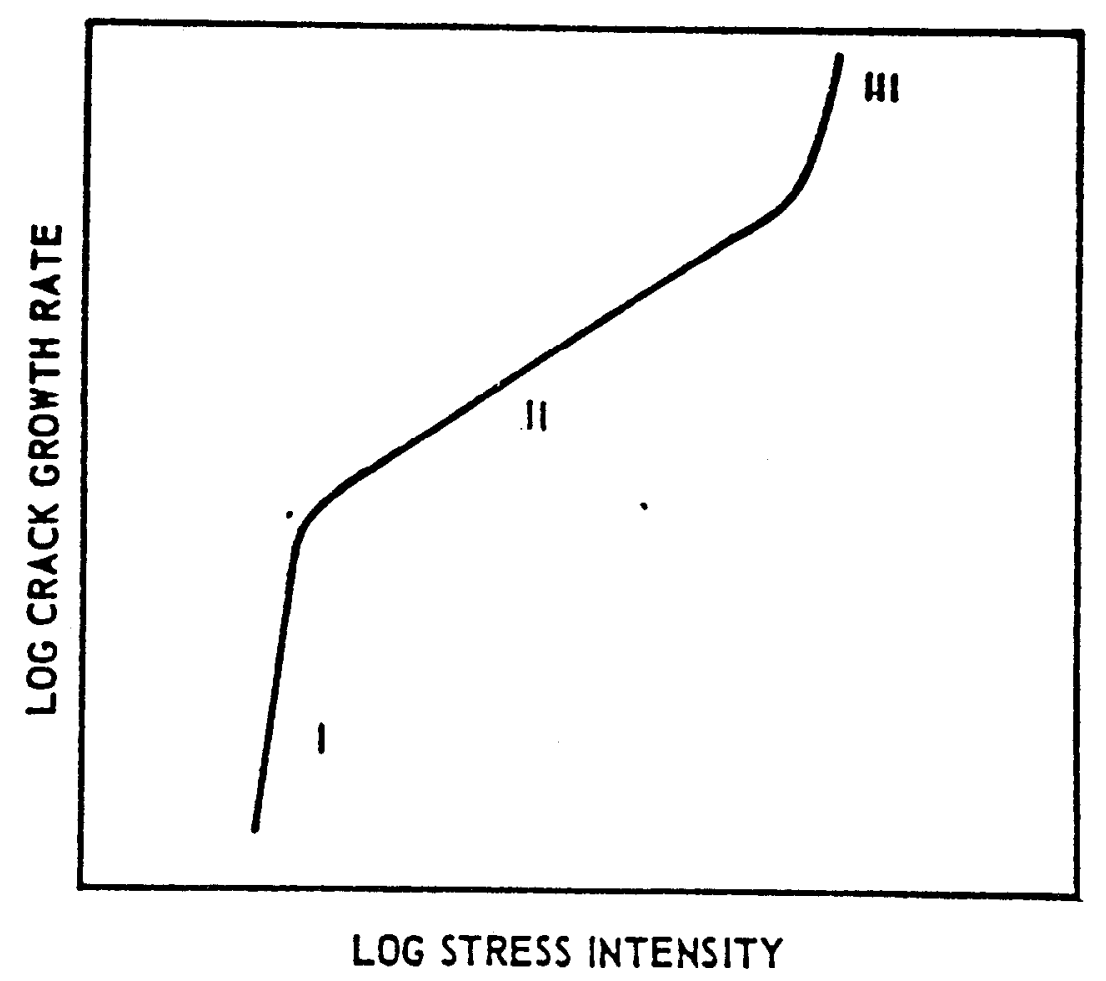

Fig. 1. Typical CCGR Behavior Found in Nicke1-base Alloys.

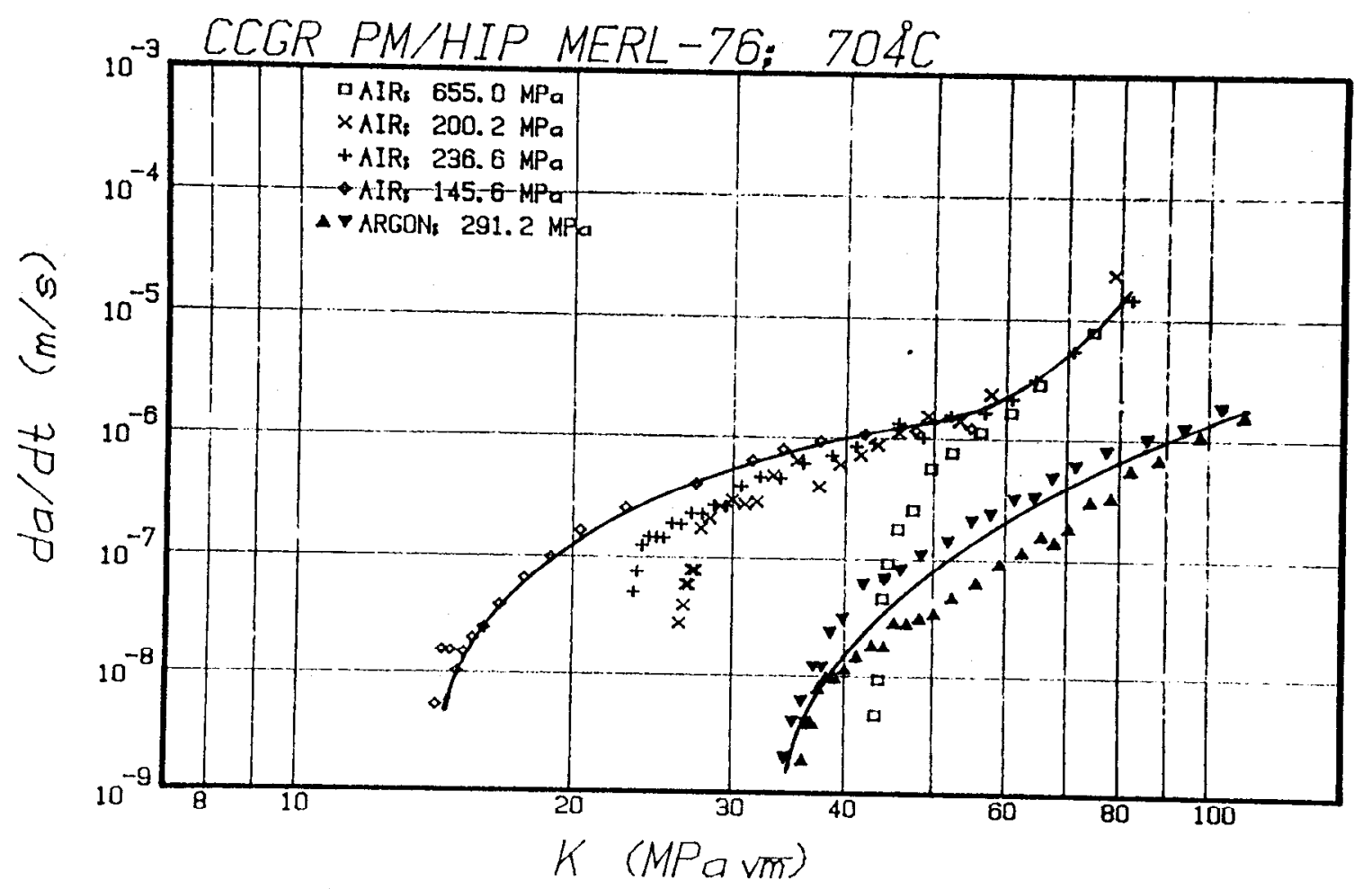

Fig. 2. CCGR Results for PM/HTP Mer1-76 in air at $704^{\circ} \mathrm{C}$ for different initial stress intensities and gross section stress. 
Table III. Alloy Chemistries and Microstructure

\begin{tabular}{|c|c|c|c|c|}
\hline & Sample 1 & Sample 2 & Sample 3 & Sample 4 \\
\hline & Astroloy & Rene 95 & Mer1-76 & $\mathrm{IN}-100$ \\
\hline Chromium & 14.8 & 14.0 & 12.2 & 12.2 \\
\hline Cobalt & 16.3 & 7.71 & 17.8 & 18.3 \\
\hline Molybdenum & 4.82 & 3.33 & 3.20 & 3.39 \\
\hline Columbium & .004 & 3.36 & 1.36 & $<.01$ \\
\hline Aluminum & 3.97 & 3.31 & 4.71 & 4.88 \\
\hline Titanium & 3.39 & 2.41 & 4.19 & 4.17 \\
\hline Hafnium & .01 & .01 & .10 & $<.01$ \\
\hline Vanadium & $<.001$ & .007 & .009 & .97 \\
\hline Carbon & .044 & .082 & .034 & .082 \\
\hline Boron & .025 & .007 & .020 & .021 \\
\hline Zirconium & .037 & .064 & .050 & .037 \\
\hline Oxygen & .0129 & .0137 & .0238 & .0111 \\
\hline Sulfur & $<.001$ & .001 & $<.001$ & $<.001$ \\
\hline Phosphorus & .014 & $<.001$ & $<.001$ & $<.001$ \\
\hline Nitrogen & .0008 & .0020 & .0029 & .0016 \\
\hline Silicon & .02 & .07 & .10 & .04 \\
\hline Iron & .24 & .18 & .077 & .082 \\
\hline Tungsten & & 3.42 & & \\
\hline Nicke1 & Remainder & Remainder & Remainder & Remainder \\
\hline$\gamma^{\prime}$ Volume Fraction & & & & \\
\hline (Calculated) & 0.50 & 0.52 & 0.58 & 0.63 \\
\hline Grain Size ( $\mu$ n) & 28 & 25 and 24 & 11 & 23 \\
\hline Prior Powder Size ( $\mu \mathrm{m})$ & 95 & 70 and 34 & 22 & 35 \\
\hline
\end{tabular}

upon the initial value of the stress intensity factor $\mathrm{K}_{\mathrm{Ii}}$, the smaller is the extent of the Stage I in the creep crack growth curve. A power law dependency of CCG, da/dt, upon the stress intensity factor, $\mathrm{K}_{\mathrm{I}}$, characterizes the Stage II of the curve. As it will be shown later, with the experimental data, a unique correlation between the CCG rates and the stress intensity factor $\mathrm{K}_{\mathrm{I}}$ is obtainable within this Stage II. Finally, the CCGR accelerates very rapidly in Stage III which corresponds to the onset of unstable fast fracture and which lasts for a very small fraction of the life of the specimen.

The creep crack growth behavior of Mer1-76 in air at $704^{\circ} \mathrm{C}$ is shown in Figure 2 which also illustrates the three stages. It is worth noticing that Stage $I$ is strongly dependent on the initial value of the stress intensity factor. The initial value of $\mathrm{K}_{\mathrm{I}_{i}}$ does not affect the correlation between $\mathrm{da} / \mathrm{dt}$ and $\mathrm{K}$ in Stage II, but it does determine the onset of this Stage II, This is to say that the values of $\mathrm{da} / \mathrm{dt}$ and $\mathrm{K}_{\perp}$ where Stage II starts depends upon the initial loading conditions. Another important feature of this process, illustrated in Figure 2 , is the rate of increase of the growth rate as a function of the stress intensity factor, is strongly dependent on the initial loading condition. Finally, it is clear that a simple correlation between $\mathrm{da} / \mathrm{dt}$ and $\mathrm{K}$ during the transient Stage $I$ does not exist.

The creep crack growth rates in air for the four PM/HIP alloys at $704^{\circ} \mathrm{C}$ are shown in Figure 3. The curves all have the same general shape. PM/HIP low carbon Astroloy and Merl-76 exhibit the slowest CCGR in air. The CCGR for the four alloys are considerably slower in the $99.999 \%$ pure argon environment, Figure 4 . Under these conditions, Mer1-76 is more resistant to CCG than low carbon Astroloy and also Rene-95 (60 mesh) than low carbon IN-100, 


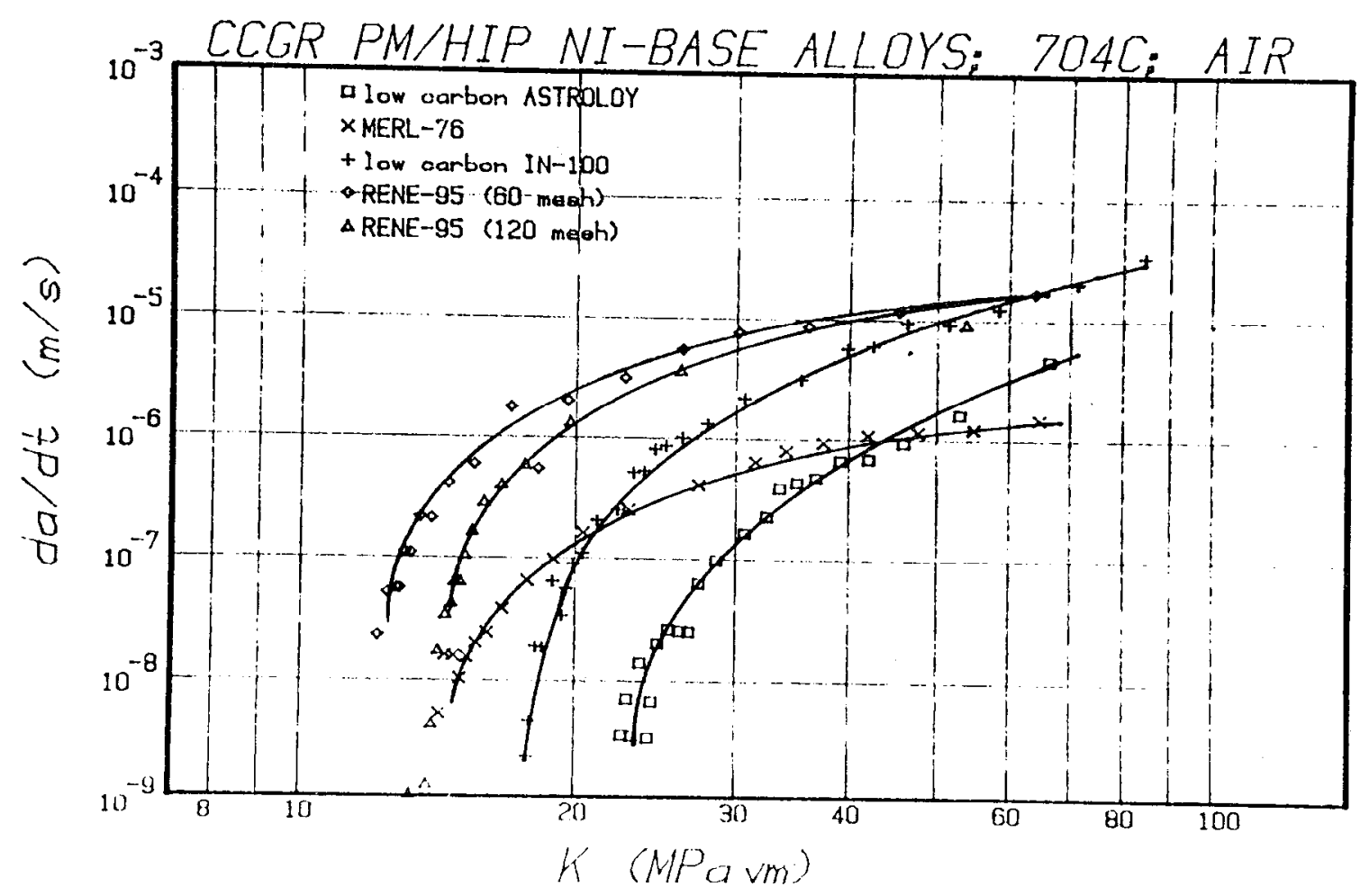

Fig. 3. CCGR Results for Five PM/HIP nickel-base superalloys in Air at $704^{\circ} \mathrm{C}$.

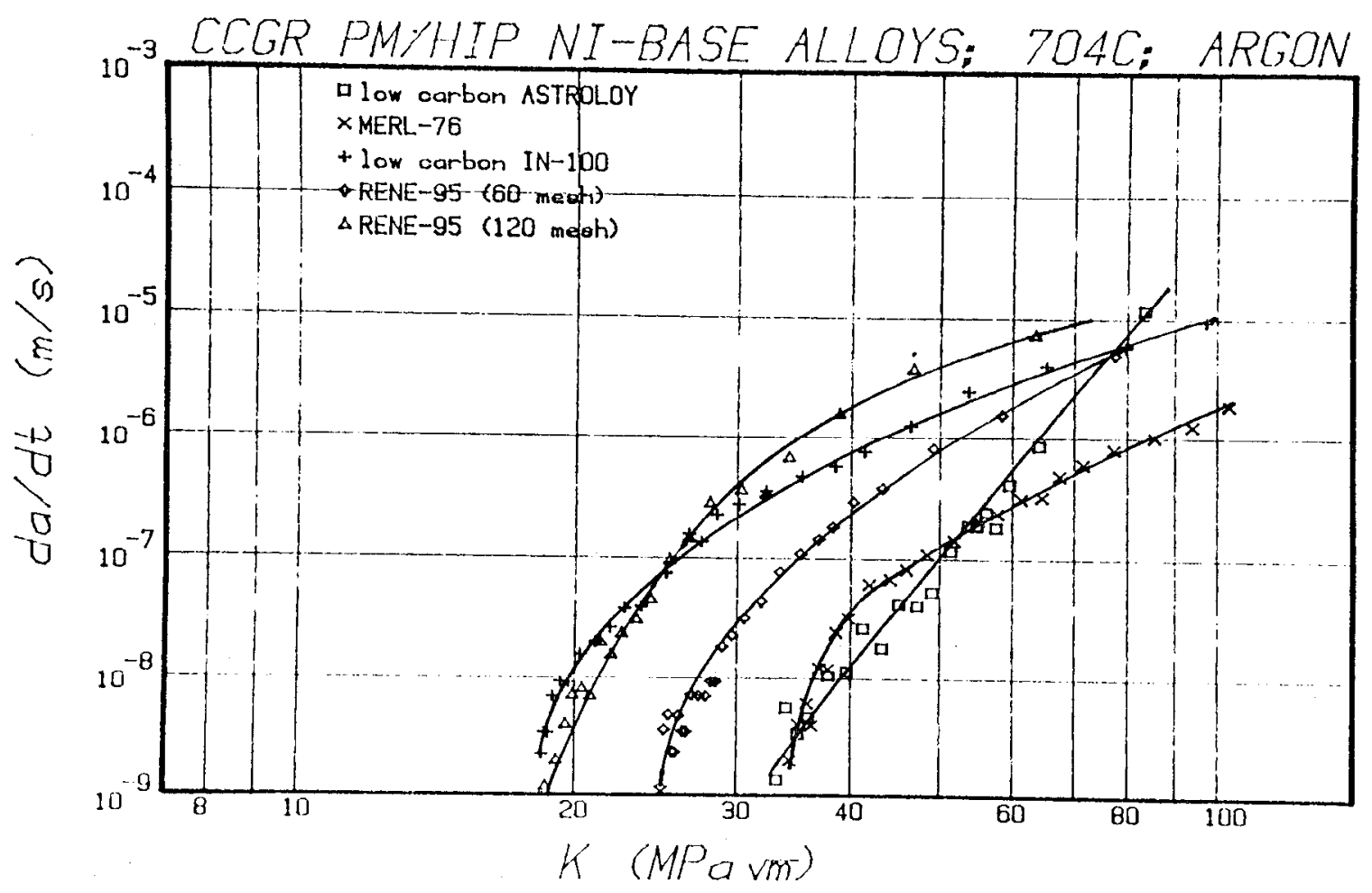

Fig. 4. CCGR resuls for Five PM/HIP Nickel-base Superalloys in $99.999 \%$ Pure Argon at $704^{\circ} \mathrm{C}$. 
The largest reduction in CCGR from air to argon is observed for the 60 mesh powder Rene 95. The exponent of the power law correlation of da/dt with $\mathrm{K}_{\mathrm{I}}$ during the Stage II regime increases from two to three in air tests to three to four for the argon tests. The fracture path was observed to change with environment. The crack followed the prior powder boundaries in the argon tests, Figure 5. In tests conducted in air, the crack followed the grain boundaries with no preference for prior powder boundaries as is seen in Figure 5 .

In general, a correlation between CCG in argon and prior powder particle sites was observed. The larger mesh powders had the slowest crack growth in argon, except for Mer1-76.

Unstressed air exposure tests of 100 hours at $704^{\circ} \mathrm{C}$ on the four alloys indicated that the oxygen diffused along the grain boundaries to a considerable depth. The depth of penetration measured by the depth of the intergranular fracture zone in a tensile test varied from alloy to alloy. The results are summarized in Table IV.

Table IV. Depth of Intergranular Embrittlement after 100 hours Exposure at $704^{\circ} \mathrm{C}$ in Air

\begin{tabular}{lcl} 
Alloy & $\begin{array}{l}\text { Average Depth of } \\
\text { Embrittlement }(\mu \mathrm{m})\end{array}$ & $\begin{array}{l}\text { Effective Calculated } \\
\text { Diffusivity: } \\
\mathrm{D}_{\mathrm{O}}=\mathrm{x}^{2} / \mathrm{t}\left(\mathrm{m}^{2} / \mathrm{s}\right)\end{array}$ \\
\cline { 2 - 3 } & 84 & $1.96 \times 10^{-14}$ \\
Low C Astroloy & 310 & $2.67 \times 10^{-13}$ \\
Mer1-76 & 720 & $1.44 \times 10^{-12}$ \\
Low C IN-100 & 840 & $1.96 \times 10^{-12}$
\end{tabular}

The experimentally determined diffusivities reflect the effect of environment on the CCGR of the four alloys. (Figure 3). Rene 95 with the highest effective oxygen diffusivity, exhibits the fastest crack growth rates in air, similarly low carbon Astroloy has the smallest effective oxygen diffusivity and the slowest CCGR in air.

\section{Discussion}

The creep crack growth rates in air for the four PM/HIP nicke1-base superalloys are faster than the rates in an inert environment. Several reasons can be advanced to explain this behavior. The most important reason, and probably best documented experimentally, is the embrittlement of the grain boundaries caused by the diffusion of oxygen at high temperatures. All four alloys used in this investigation were produced by powder metallurgy. The prior particle boundaries are by the nature of the processing technique the weak links of the material due to the presence of inclusions and to contamination of the particle's surface. The ability of the material to relax stresses by creep may also be more limited along the particle boundaries and naturally fracture initiates first at these locations. Consequently, the fracture path in inert environment was observed along the prior particle boundary. In air, oxygen diffuses along all the grain boundaries near the crack tip. Embrittlement by oxygen causes the grain boundaries to become weaker than the prior particle boundaries which results in a change of the fracture path and acceleration of the CCGR. 
(a)

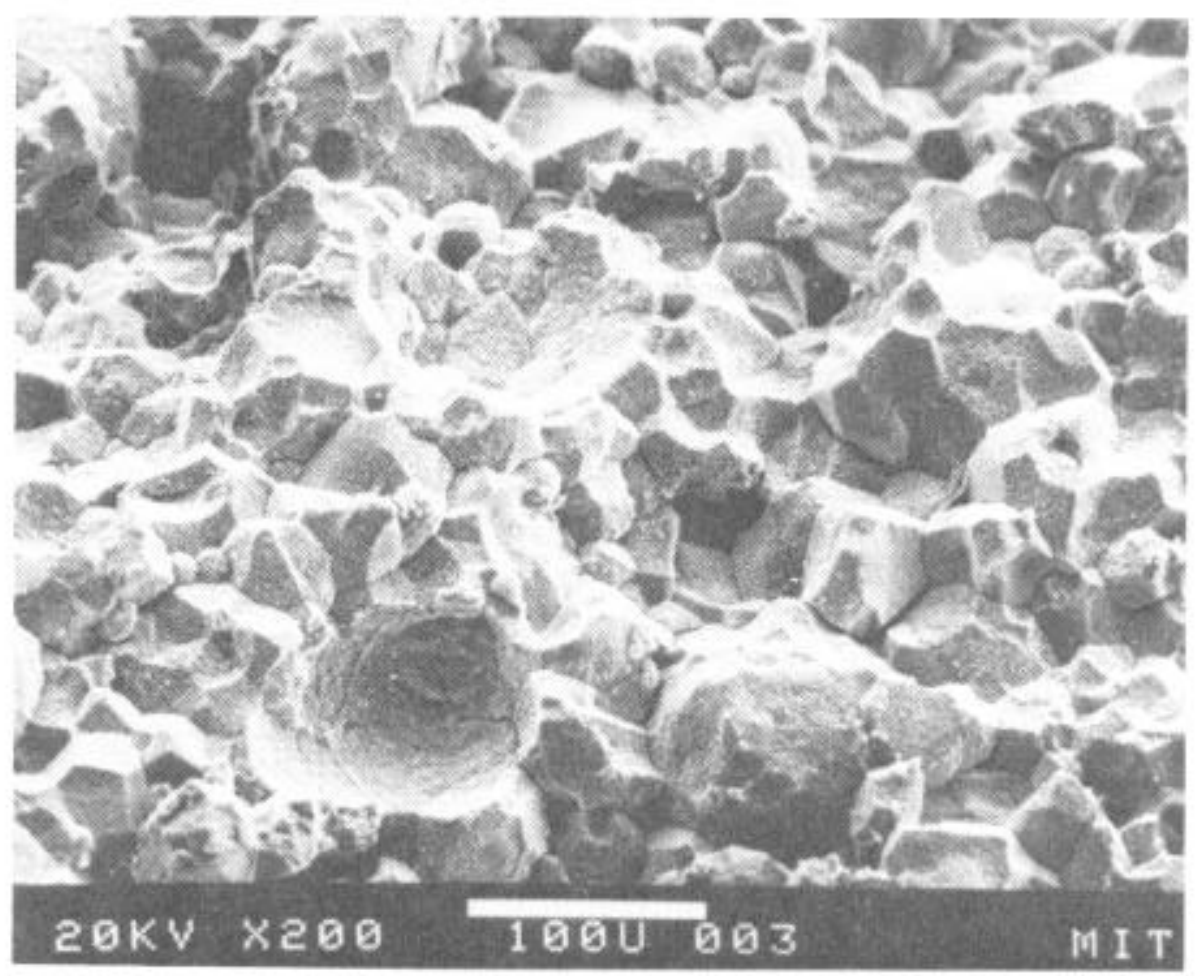

(b)

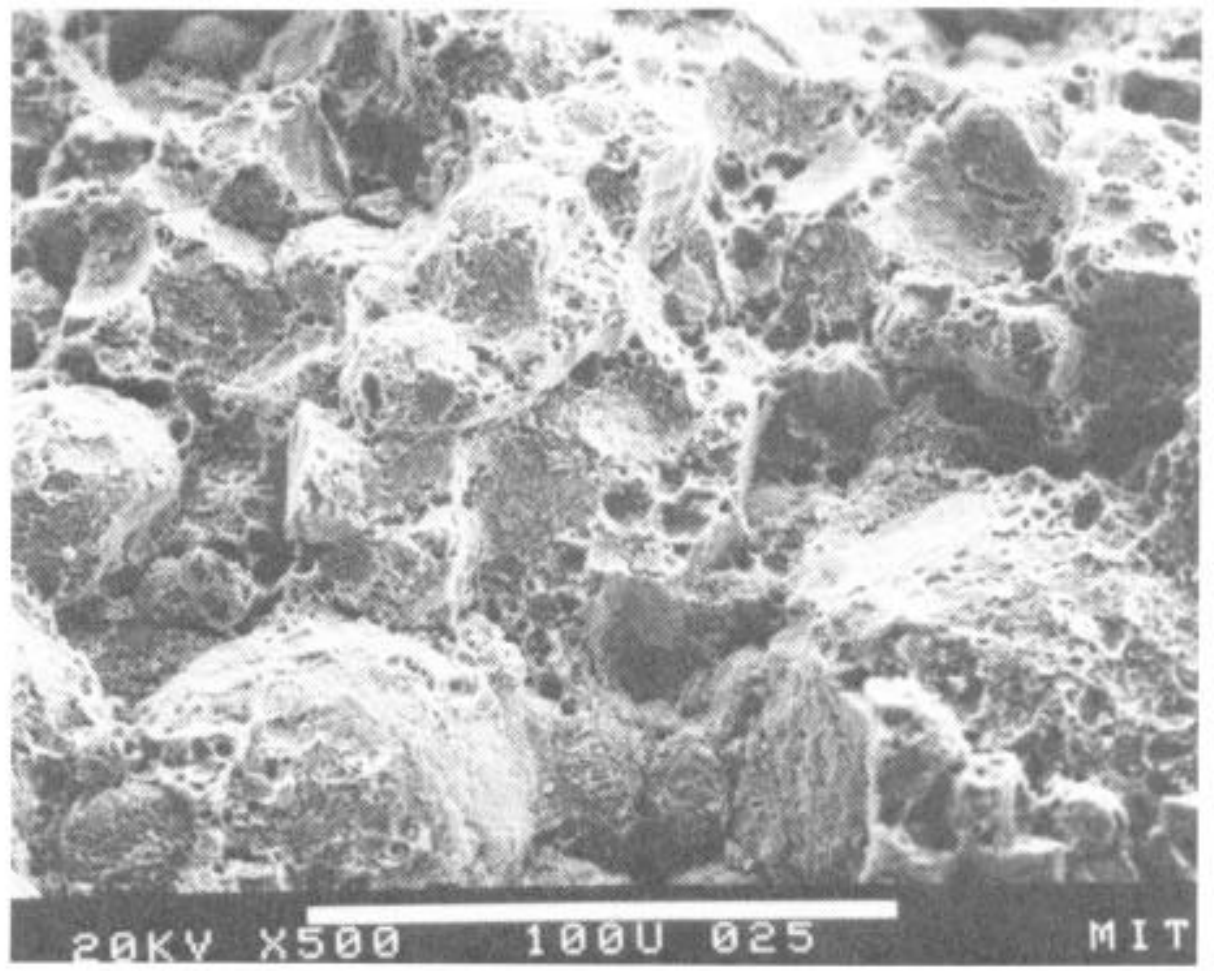

Fig. 5. Fractographs of PM/HIP Low C Astroloy at $704^{\circ} \mathrm{C}$
(a) in air;
(b) in argon. 
The effect of environment measured by the relative increase of CCGR in air was different for the four alloys. Low carbon Astroloy was the least susceptible to the oxygen embrittlement and Rene-95 exhibited the most drastic increase in CCGR in air. As can be seen in Table III, the four alloys had different contents of boron and zirconium. Alloying additions such as boron and zirconium have been shown to inhibit oxygen embrittlement (2i) and therefore elements can be expected to reduce the CCGR in oxygen containing environments. Using the grain boundary concentration of boron in low carbon Astroloy as a reference value, we have calculated the ratio of grain boundary boron concentration of the other alloys with respect to Astroloy. The results are given in Table $V$.

$\frac{\text { Table V. Crain Boundary Boron Concentration with }}{\text { Respect to Low Carbon Astroloy }}$

\begin{tabular}{lc} 
Alloy & w/o B in $g \cdot b \cdot$ \\
\cline { 2 - 2 } Astroloy & w/o B in 1.c.Astroloy \\
Mer $1-76$ & 1.0 \\
IN-100 & 3.0 \\
Rene 95 & 0.7 \\
\end{tabular}

The results reflect very much the observed changes in CCGR from argon to air. The exact mechanisms and kinetics of the oxygen diffusion are yet unknown and additional work is required.

\section{Conclusions}

1. Creep crack growth rates were measured for four $\gamma-\gamma^{\prime}$ strengthened nickel base superalloys at $704^{\circ} \mathrm{C}$ in both air and in a $99.999 \%$ pure argon environment. The four alloys tested were all PM/HIP alloys and they included low carbon Astroloy, Mer1-76, low carbon IN-100, Rene 95 (60 mesh powder), and Rene-95 (120 mesh powder). The CCGR ranged from $10^{-9} \mathrm{~m} / \mathrm{s}$ to $10^{-4} \mathrm{~m} / \mathrm{s}$ when the stress intensity factor ranged from $10 \mathrm{MPa} \sqrt{\mathrm{m}}$ to $100 \mathrm{MPa} \sqrt{\mathrm{m}}$. The presence of oxygen during CCG resulted in an increase in the measured CCGR for a given $\mathrm{K}$ in all the alloys tested over the CCGR in pure argon.

2. The creep crack growth rate behavior of nickel-base alloys exhibited three stages. Stage $I$ is all initial transient which is not a unique $f u n c-$ tion of $\mathrm{K}$ and which strongly depends up on the initial loading condition. Stage II is a region of gradually increasing CCGR with $K$ and Stage III is associated with fast fracture.

3. The increase in the measured CCGR in air as compared to the argon environment resulted from a change in fracture path and a decrease in ductility. The fracture path was along the prior powder particle boundaries in argon tests, and along the grain boundaries in the air tests.

4. The grain boundary chemistry of an alloy is critical in determining its susceptibility to oxygen embrittlement. Alloys with high concentrations of boron tend to be more creep crack growth resistant in air than alloys with a low boron content.

\section{Acknowledgment}

The authors gratefully acknowledge the Air Force office of Scientific Research and the National Science Foundation-Materials Research Laboratory for the generous support of this work. 


\section{References}

1. D. McLean, B. F. Dyson, and M. R. Taplin, Fracture 1977, Vol. 1, ICF4, Waterloo, Canada, p. 325.

2. A. S. Argon, Scripta Met, 17, 1983, p. 5.

3. W. D. Nix, D. K. Matlock, and R. J. Dimel[i, Acla Meta11, 25, 1977 , p. 495 .

4. J. L. Bassani, Creep and Fracture of Engineering Materials and Structures, ed. by B. Wilshire and D. R. Owens, Pineridge Press, Swansea, England, 1981, p. 329 .

5. R. Raj and S. Baik, Met. Sci. J., 14, 1980, p. 385.

6. C. C. Annis, Jr, , M. C. Van Wanderham, J。A, Harris, Jr, , and C, T. Sims, "Gas-Turbine Disk Retirement-for-Cause: An Application of Fracture Mechanics and NDE", A.S.M.E., 1980,

7. K. R. Bain and R. M. Pe1loux, Met, Traris, A, 15A, 1984

8. R. M. Pelloux and J. C. Huang, "Creep-Fatigue-Environment Interactions", ed. R. M. Pelloux and N. S. Stoloff, A.I.M.E., 1980, P.151。

9. S. F1oreen and C, J. White, Met. Trans.A, 12A, 1981, p. 1973,

10. F, Gabrielli and R. M, Pelloux, Met, Trans, A, 13A, 1982, p. 1083.

11. C. C. Law and M. J. Blackburn, Met. Trans. A, 11A, 1980, P, 495.

12. R. C. Donath, J. Nicholas, and C, S, Fu, Fracture Mechanics: Thirteenth Conference, ASTM STP 743, ed, R. Roberts, p, 186.

13. R. B. Scarlin, Mat. Sci, and Eng, 30, 1977, p, 55,

14. K. Sadananda and P. Shahinian, Met. Trans, A, 11A, 1980, p. 267.

15. K. Sadananda and P. Shahinian, "Crack Growth Under Creep and Fatigue Conditions", in Creep-Fatigue-Environment Interactions, ed, by R. M. Pelloux and N.S. Stoloff, A.I.M.E, 1980, P. 86.

16. S. Floreen, Met. Trans. A, 6A, 1975, p. 1741.

17. M. Prager and G. Sines, Journal of Basic Eng., 1971, p. 225.

18. P. Shahinian, Transactions of the ASME, 1965, p. 344.

19. P. N. Chaka and C. J. McMahon, Jr., Met. Trans. A, 5,1974, p. 441.

20. D. A. Woodford and R. H. Brickne11, Met. Trans. A, 12A, 1981, p. 1467.

21. R. H. Bricknel1 and D. A. Woodford, Met. Trans. A, 12A, 1981, p. 425.

22. D. A. Woodford, Met. Trans. A, 1]A, 1981, p. 299. 